\title{
Tumor-infiltrating B cells as a favorable prognostic biomarker in breast cancer: a systematic review and meta-analysis
}

You Qin ${ }^{1 \dagger}$, Fei Peng ${ }^{2 \dagger}$, Lisha Ai ${ }^{2^{*}} \mathbb{D}$, Shidai Mu², Yuting $\mathrm{Li}^{1}$, Chensu Yang ${ }^{1}$ and $\mathrm{Yu} \mathrm{Hu}^{2^{*}}$

\begin{abstract}
Background: Tumor-infiltrating B lymphocytes (TIL-Bs) is a heterogeneous population of lymphocytes. The prognostic value of TIL-Bs in patients with breast cancer remains controversial. Here we conducted this meta-analysis to clarify the association of TIL-Bs with outcomes of patients with breast cancer.

Methods: We searched PubMed, Embase, and Web of Science to identify relevant studies assessing the prognostic significance of TIL-Bs in patients with breast cancer. Fixed- or random-effects models were used to evaluate the pooled hazard ratios (HRs) for overall survival (OS), breast cancer-specific survival (BCSS), disease-free survival (DFS), and relapse-free survival (RFS) in breast cancer.
\end{abstract}

Results: A total of 8 studies including 2628 patients were included in our study. Pooled analyses revealed that high level of TIL-Bs was associated with longer OS (pooled HR=0.42,95\% Cl 0.24-0.60), BCSS (pooled HR=0.66, 95\% Cl $0.47-0.85$ ), and DFS/RFS (pooled $\mathrm{HR}=0.41,95 \% \mathrm{Cl} 0.27-0.55$ ).

Conclusions: This meta-analysis suggests that TIL-Bs could be a promising prognostic marker for breast cancer. Novel therapeutic strategies for breast cancer treatment could be developed by enhancement of B cell-mediated antitumor immunity.

Keywords: Tumor-infiltrating B lymphocytes, Breast cancer, Meta-analysis, Prognosis

\section{Introduction}

Breast cancer (BC) is a group of malignant diseases arising from the mammary gland [1]. With over 200, 000 new cases each year across the world, it is the most frequent malignancies among women, accounting for $22 \%$ of all female cancer types [2]. Despite the recent striking improvements in therapeutic modalities, $\mathrm{BC}$ is still the leading cause of cancer-related death worldwide among women $[2,3]$.

\footnotetext{
*Correspondence: ailisha@hust.edu.cn; dr_huyu@126.com

${ }^{\dagger}$ You Qin and Fei Peng contributed equally to this work

${ }^{2}$ Institute of Hematology, Union Hospital, Tongji Medical College,

Huazhong University of Science and Technology, No. 1277 Jiefang Avenue, Hubei 430022 Wuhan, China

Full list of author information is available at the end of the article
}

The comprehensive understanding of the immune responses in cancer initiation and progression has only advanced during recent years [4], even though tumorinfiltrating immune cells were reported by Rudolf Virchow over 100 years ago in $1863[5,6]$. The presence of tumor-infiltrating lymphocytes (TILs) at diagnosis is correlated with improved survival after adjuvant systemic therapy and pathological complete responses to neoadjuvant chemotherapy in BC [7-10]. These findings have provided substantial evidence of the protective potential of lymphocytes within tumors.

$\mathrm{B}$ cell is one of the main immune components, occupying a central position in forming the tumor immune microenvironment $[11,12]$. Both antitumor and tumorpromoting functions of $\mathrm{B}$ cells have been reported in tumor immunity and immunotherapy [11]. Evidence

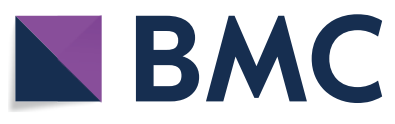

c) The Author(s) 2021. This article is licensed under a Creative Commons Attribution 4.0 International License, which permits use, sharing, adaptation, distribution and reproduction in any medium or format, as long as you give appropriate credit to the original author(s) and the source, provide a link to the Creative Commons licence, and indicate if changes were made. The images or other third party material in this article are included in the article's Creative Commons licence, unless indicated otherwise in a credit line to the material. If material is not included in the article's Creative Commons licence and your intended use is not permitted by statutory regulation or exceeds the permitted use, you will need to obtain permission directly from the copyright holder. To view a copy of this licence, visit http://creativeco mmons.org/licenses/by/4.0/. The Creative Commons Public Domain Dedication waiver (http://creativecommons.org/publicdomain/ zero/1.0/) applies to the data made available in this article, unless otherwise stated in a credit line to the data. 
accumulating in the late $1990 \mathrm{~s}$ facilitated a widespread acceptance of B cell-mediated protumor functions [13]. However, more recent publications have shown that $B$ cells employ a protective rather than a detrimental property in human solid tumors [14-18]. Intriguingly, there exists considerable controversy over the prognostic impacts of TIL-Bs in different cancer types or subtypes including BC [19-21].

Growing evidence has revealed that TIL-B is a positive prognostic indicator in human $\mathrm{BC}$. For example, in inflammatory breast cancer (IBC), CD20+TIL represents a prognostic factor of better outcomes [22]. Similarly, a separate study shows that high levels of TIL-Bs are associated with improved prognosis of $\mathrm{BC}$ patients [23]. A B-cell metagene has been shown prognostic value for node-negative $\mathrm{BC}$ with high proliferative activity [24]. This was followed by an immunochemistry (IHC) study associating an increased total number of TIL-Bs with significantly better breast cancer-specific survival (BCSS) in basal-like, estrogen receptors negative (ER), and HER2 + cancer patients [25]. In contrast to these studies, Miligy et al. have shown that preinvasive ductal carcinoma in situ associated with increased TIL-Bs had poorer recurrence-free survival [26].

Clarifying the prognostic role of TIL-Bs could improve the understanding of $B$ cells in antitumor responses, with help of developing more effective immunotherapies for $\mathrm{BC}$. To this end, we conducted the present meta-analysis, showing that higher densities of TIL-Bs were significantly associated with prolonged overall survival (OS), BCSS, disease-free survival (DFS), and relapse-free survival (RFS) in BC patients. This finding suggests that B cells function in antitumor response and might be a promising source for novel therapeutic strategies for BC patients.

\section{Methods}

\section{Search strategy}

We conducted this meta-analysis following the search strategies [27] and the Preferred Reporting Items for Systematic Reviews and Meta-Analyses (PRISMA) guidelines [28]. PubMed, Embase, and Web of Science were searched without limits to identify all relevant studies until October 2020. Detailed search strategy was shown in Additional file 1. Keywords used in the search process are as follow: "B cells" (e.g., "tumor-infiltrating B cells" "TIL-Bs" "B lymphocytes" "intratumoral B lymphocytes"), "prognosis" (e.g., "survival" "mortality" "outcome" "progression" "recurrence" "metastasis") and "breast cancer" (e.g., "breast carcinoma" "carcinoma of the breast" "breast ductal carcinoma"). We also explored references from previously published meta-analyses and reviews to find more potential studies.

\section{Selection and exclusion criteria}

Studies meeting the following criteria were included: (i) studies reported the association between TIL-Bs and prognostic parameters in breast cancer; (ii) HR and 95\% confidence intervals (CI) were reported or could be reconstructed by $\mathrm{p}$ values and other data reported; (iii)studies applied IHC as a detection method and used CD20 as a molecular marker of B cells; (iv) the sample size of studies was greater than 50. Exclusion criteria were: (i) Conference abstracts, reviews, case reports, letters, animal trials, etc.; (ii) studies without specific or sufficient data concerning breast cancer or TIL-Bs; (iii) studies were excluded if the sample size $<50$, to reduce publication bias caused by small sample size; (iv) Only the most recent publication was enrolled in this metaanalysis if one patient cohort were investigated by several studies.

\section{Data extraction}

Data extraction was performed by two independent reviewers (You Qin and Lisha Ai). The disagreement was resolved by discussion with the other investigator (Fei Peng) until the two reviewers reached a consensus or by consulting experts if necessary. A data abstraction form was predefined with key elements such as the first author's name, year of publication, country of publication, types of breast cancer, sample size, patient age, follow-up duration, cut-off value, and survival data including OS, BCSS, DFS, and RFS. BCSS was defined as the time between breast cancer diagnosis and death due to breast cancer, while OS was the period between diagnosis and death due to all causes (including breast cancer). DFS was the period after curative treatment when no disease can be detected. RFS was defined as the interval between the date of initial treatment and the data of recurrence or death from any cause; We used HR and 95\% CI directly If they were reported in the study; Otherwise, we reconstructed the data from Kaplan-Meier curves and $\mathrm{p}$ values using the software Engauge Digitizer version 4.1 [29].

Quality of evidence was assessed by the NewcastleOttawa Scale (NOS) [30]. Based on this scale, each study is evaluated on several domains, including the comparability of groups, the selection of participants, the ascertainment of outcomes of interest, et al. Studies can be scored for each domain. A study is considered high-quality if there is a score of 6 or more (the maximum score is 9).

\section{Statistical analysis}

This meta-analysis was conducted using STATA statistical software (version12.0; Stata Corporation, College 
Station, TX). The prognostic effects of TIL-Bs in breast cancer were evaluated by HRs and $95 \%$ CIs. HR was considered as the risk ratio between patients with rich TIL-Bs versus those with low TIL-Bs. Thus, an $\mathrm{HR}<1$ implied TIL-Bs as a good prognosis, whereas an HR $>1$ implied TIL-Bs as a poor prognosis. We assessed the heterogeneity by using the $\chi^{2}$-based $\mathrm{Q}$ test and the $I^{2}$ test. Statistically significant heterogeneity was defined as $I^{2}$ was greater than $50 \%$ and/or $P$ value was less than 0.05 . Then sensitivity analysis and subgroup analysis were performed to assess the source of heterogeneity. Publication bias was also quantified by Begg's tests and Funnel plot.

\section{Results}

\section{Search results}

A total of 378 studies were identified after the initial search. After exclusion of the duplicate records $(\mathrm{n}=190)$; letters, conference abstracts, reviews, etc. $(\mathrm{n}=49)$; and the studies not relevant to topics $(\mathrm{n}=112)$, the remaining studies $(n=27)$ were left for full-text evaluation. Then 19 full-text articles were removed for reasons: no available data, no specific data concerning breast cancer or B cells, and overlapped patients. At last, 8 studies between 2012 and 2020 were enrolled in the current meta-analysis [22, 23, 25, 31-35]. The process of the literature search was shown in Fig. 1. One research reported two cohorts of breast cancer patients (TNBC cohort and HER2 + cohort), thus we treated it as two studies [31].

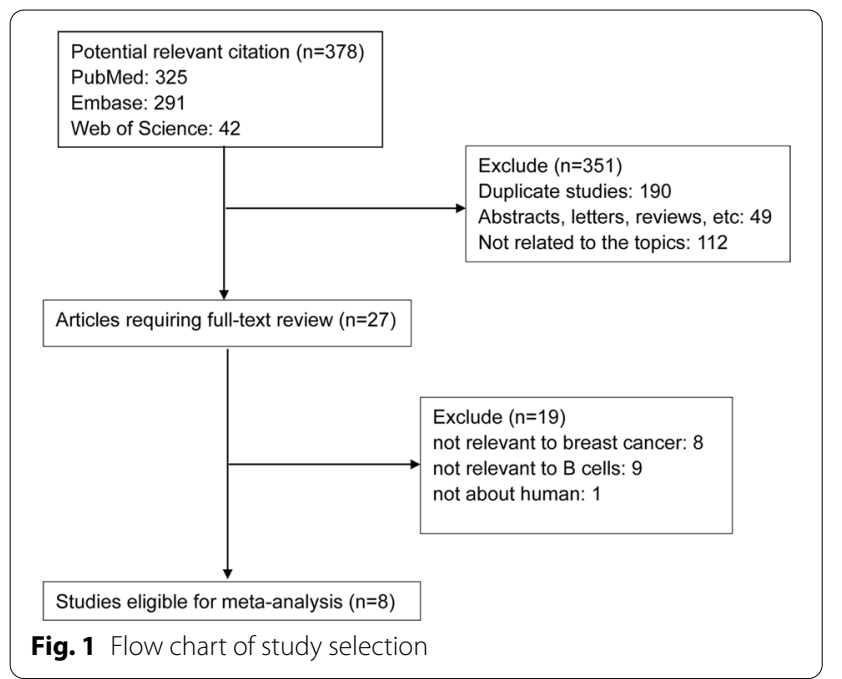

\section{Study characteristics}

The total sample size was 2,628, ranging from 102 to 1214. All these studies were retrospective analysis of breast cancer. Nine studies enrolled $>100$ patients and one study even enrolled $>1000$ patients [25]. All these studies were retrospective analysis of breast cancer. These studies were single-center studies, and conducted in the UK [25, 32], Belgium [31], France [23], Singapore [35], Algeria [22], and China [33, 34], which evaluated several types of breast cancer, including TNBC, HER2 + breast cancer, invasive ductal carcinoma of the breast, and breast ductal carcinoma in situ. The cutoff value of TILBs ranged from 1 to $5.5 \%$ or 1 cell to 115 cells. Six studies reported the prognostic value of TIL-Bs on OS [22, 31, 33-35], two studies showed the association between TILBs and BCSS [25, 32], six studies evaluate the prognostic effects of TIL-Bs on DFS [22, 31, 33-35], and one study reported RFS [23]. Seven studies reported HR and 95\% CI directly in the original paper. Eight studies had a NOS score $\geq 6$. The characteristics of these studies were shown in Table 1.

\section{TIL-Bs and survival of $B C$ patients}

Nine studies explored the association between TIL-Bs and survival of patients with BC. Figure 2 summarized HR for OS in 6 studies (HR $=0.42,95 \%$ CI $0.24-0.60)$ and BCSS in two studies (HR $=0.66,95 \%$ CI $0.47-0.85)$, and there was no heterogeneity among the studies $\left(I^{2}=0 \%\right.$, $\mathrm{P}_{\text {heterogeneity }}=0.783$; and $I^{2}=0 \%, \mathrm{P}_{\text {heterogeneity }}=0.385$, respectively). In addition, as shown in Fig. 3 , the combined results of 7 studies showed higher levels of TIL-Bs were associated with longer DFS/RFS (HR $=0.41,95 \%$ CI $0.27-0.55)$ without significant heterogeneity $\left(I^{2}=0 \%\right.$, $\left.\mathrm{P}_{\text {heterogeneity }}=0.924\right)$. These results suggested that a higher TIL-Bs level was significantly correlated with better survival in patients with $\mathrm{BC}$.

\section{Sensitivity analysis}

Sensitivity analyses were then carried out to assess the influence of every single study on the pooled HRs. As shown in Figs. 4, the pooled HRs were not significantly altered by any individual study, indicating the stability of our results.

\section{Publication bias}

Begg's funnel plots were conducted to explore the publication bias of the included studies (Fig. 5). The results show that there was no significant asymmetry, and the rank correlation tests were not significant $(P=0.175)$, indicating no significant evidence of publication bias. 


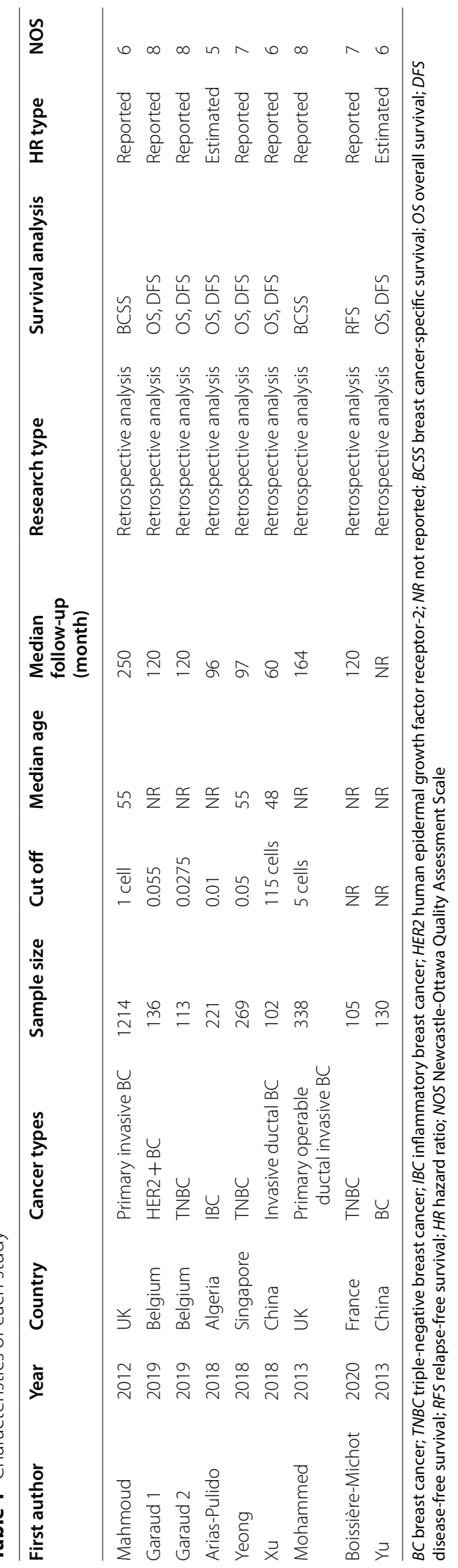




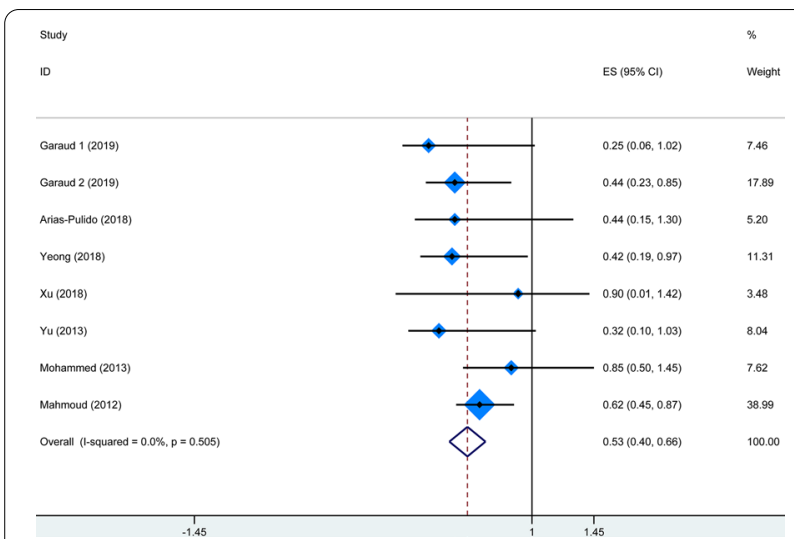

Fig. 2 Forest plot for the association of TIL-Bs with OS and BCSS in BC patients

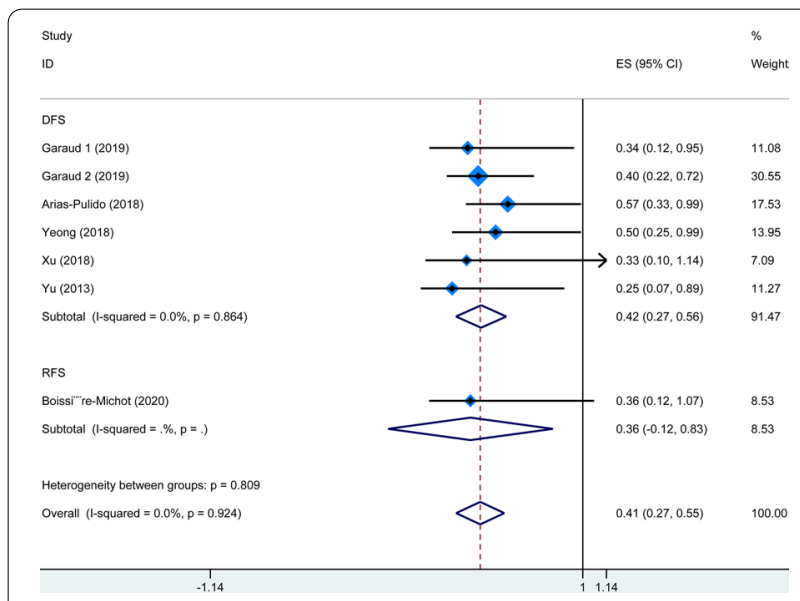

Fig. 3 Forest plot for the association of TIL-Bs with DFS/RFS in BC patients

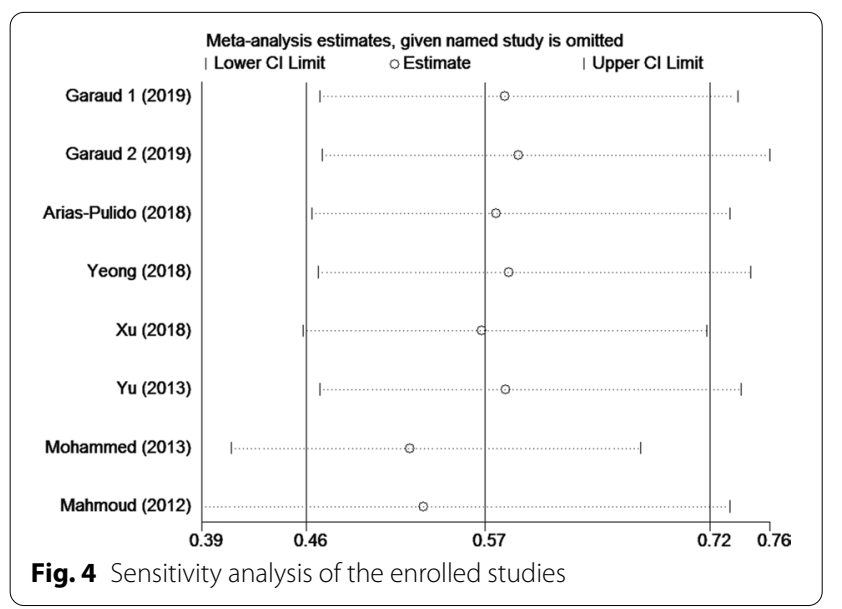

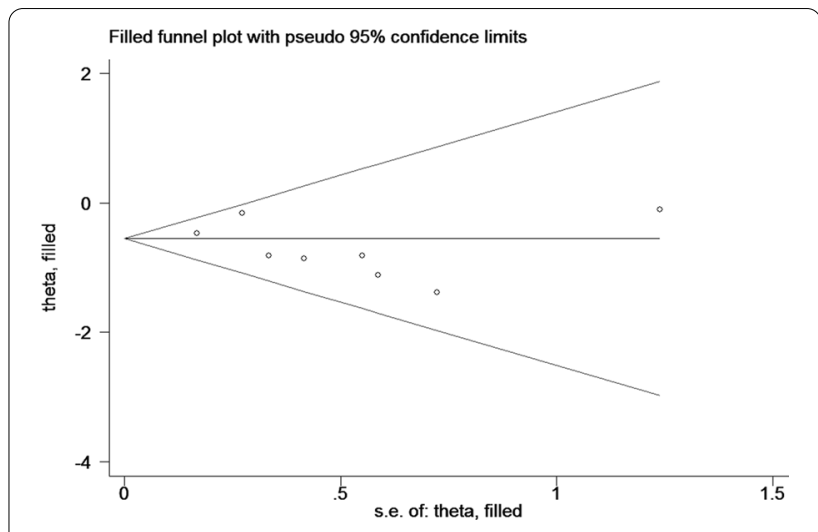

Fig. 5 Funnel plot with trim and fill

\section{Discussion}

The initiation and development of breast cancer are derived not only by the genetic abnormalities but also by interplays between cancer cells and their surrounding tumor microenvironment (TME) [36], which is comprised of a variety of tissues and cell types, including blood vessels, fibroblasts, extracellular matrix, and immune cells [37]. Accumulating evidence has shown that the infiltrates of lymphocytes, such as $\mathrm{T}$ cells, dendritic cells, macrophages, and B cells, occupy a central position in promoting or suppressing tumorigenesis and cancer progression [37]. Thus, targeting and remodeling the tumor immune microenvironment is a promising strategy to develop novel immunotherapies for cancers. It has been well recognized that cytotoxic CD8 $+\mathrm{T}$ cells confer antitumor immunity [38]. Although both $\mathrm{T}$ cells and B cells take part in tumorigenesis, relatively limited studies have focused on B cell-mediated antitumor or protumor responses [39]. Additionally, both positive and negative prognostic significance of TIL-Bs has been reported in human solid tumors [20,21,40], including $\mathrm{BC}$, resulting in differing opinions concerning whether cancer immunotherapies should be designed to promote or suppress B cells [21].

To make sense of the current controversial findings, we conducted the present systematic review and metaanalysis to verify the contribution of intratumor B cells to the prognosis of $\mathrm{BC}$ patients. We comprehensively searched the databases (e.g., PubMed, Embase, and Web of Science) and finally included 8 eligible cohort studies addressing the association of TIL-Bs with the survival of $B C$ patients utilizing $B$ cell marker CD20 tested by IHC. The pooled analysis showed that high levels of TIL-Bs were significantly correlated with the favorable OS, BCSS, DFS, and RFS of patients with $\mathrm{BC}$, suggesting that $\mathrm{B}$ cells within tumor tissue might exert antitumor immunity. 
Although both antitumor and protumor-promoting activities of TIL-Bs have been reported in tumor immunity and immunotherapy [11], more recent findings have demonstrated that $\mathrm{B}$ cells employ a protective rather than a detrimental property in human solid tumors [14-18], which can properly explain the positive prognostic value of TIL-Bs in BC shown in our meta-analysis. TIL-Bs exert antitumor functions via direct tumor-killing effects, antigen presentation, antibody production, cytokine secretion, and other activities [41-43]. First, it has been reported that activated $\mathrm{B}$ cells have the potential to directly kill tumor cells via antibody-independent mechanisms [44-49], which provides the possibility for adoptive cellular therapy based on B cells. Tao and his colleagues reported that effector B cells directly killed tumor cells via the Fas/FasL and CXCR4/CXCL12 pathways, and the killing activities can be improved by IL-2 and inhibited by IL-10 [44-49]. Second, B cells have been proved to function as antigen-presenting cells (APCs) to engage with $\mathrm{T}$ cells, triggering anti-cancer responses. Human B cells can efficiently present peptides to CD4 $+\mathrm{T}$ cells after activated by CD40 ligand and pulsed with tumor antigens [50]. Colluru and colleagues successfully applied $\mathrm{B}$ cells as a tool to present tumor DNA to CD8 + T cells as a vaccine, which elicited an antitumor effect in vivo [51]. In another report, B cells were reported to infiltrate into the brain tumor site, where they promoted $\mathrm{T}$ cellinduced tumor killing as APCs [52]. Third, Multiple lines of evidence have demonstrated that B cells within tumorrelated tertiary lymphoid structures can be converted to antibody-producing memory B cells or plasma cells after exposure to tumor-associated antigens [53, 54], thus producing antitumor antibodies within tumor sites and meditating tumor-killing effect [11].

Meanwhile, intratumoral B cells and antibodies may also act as immunosuppressive players [55], thereby driving tumor growth. B cells with protumor properties are mostly described as regulatory B cells (Bregs), which have been identified by cell surface markers and secretion of cytokines, functioning by suppressing immune responses and promoting tumor progression [56-60]. Clinical cohort studies report that Breg enhancement in the TME predicts poorer outcomes in cancer patients [58, 61, 62], suggesting that Bregs might actively participate in tumor immune escape. More specific markers regarding different B cell subsets deserve extensive study to precisely investigate the role of various $B$ cell subpopulations in the prognosis of $\mathrm{BC}$ patients.

Some limitations should be noted in this systematic review and meta-analysis, requiring careful interpretations of the results. First, the cut-off value for defining a high level of TIL-Bs varied among the enrolled studies. Second, our results may somewhat overestimate the prognostic significance of TIL-Bs in BC patients, because most of the included studies reported positive results. Third, all the enrolled studies were retrospective, and thus well-designed prospective studies are needed to further investigate the association between TILs-B and survival of breast cancer. Finally, only 4 out of 8 included studies have provided the molecular subtypes of $\mathrm{BC}$, leading to insufficient analysis of the prognostic impact of TIL-Bs in different specific subtypes. Despite the above limitations, the present metaanalysis supports TIL-Bs as a biomarker for predicting survival in $\mathrm{BC}$ patients due to the convincible results as well as the easy-going detection method IHC of TIL-Bs.

\section{Conclusions}

To our best knowledge, this is the first meta-analysis to pool analyze the prognostic role of TIL-Bs in BC patients. Here, we comprehensively searched databases for relevant studies, and included8 cohort studies with a total of 2,628 patients for the current meta-analysis, concluding that $\mathrm{BC}$ patients with elevated TIL-Bs have prolonged survival, which could help to stratify the patients into different categories and select personalized cancer therapies. More importantly, novel anti-BC therapeutic strategies would be developed by enhancement of B cell-mediated antitumor immunity. More multicenter prospective cohort studies should be conducted to further verify the role of TIL-Bs in different molecular subtypes of BC.

\section{Abbreviations \\ BC: Breast cancer; TILs: Tumor-infiltrating lymphocytes; TIL-Bs: Tumor-infiltrat- ing B lymphocytes; TNBC: Triple-negative breast cancer; IBC: Inflammatory breast cancer; IHC: Immunochemistry; BCSS: Breast cancer-specific survival; ER: Estrogen receptor; PR: Progesterone receptor; HER2: Human epidermal growth factor receptor-2; OS: Overall survival; DFS: Disease-free survival; RFS: Relapse-free survival; HR: Hazard ratio; TME: Tumor microenvironment; APCs: Antigen-presenting cells; Bregs: Regulatory B cells.}

\section{Supplementary Information}

The online version contains supplementary material available at https://doi. org/10.1186/s12935-021-02004-9.

Additional file 1. Search strategy

\section{Acknowledgements}

We would like to thank the researchers and study participants for their contributions.

\section{Authors' contributions}

$\mathrm{LA}$ and $\mathrm{YH}$ conceived and designed this study. $Y Q, L A$, and FP identified eligible literature, obtained datasets, and had full access to them. LA, YL, CY, and

$S M$ carried out the analyses. $Y Q$ and $L A$ drafted the report with advice from $Y H$. $F P, Y L, C Y$, and SM contributed to revising the manuscript. All authors read and approved the final manuscript. 


\section{Funding}

This work was supported by grants of the National Natural Science Foundation of China (No. 81500172 to Lisha Ai; No. 81202962 to You Qin).

\section{Availability of data and materials}

Please contact the author for data requests.

\section{Declarations}

\section{Ethics approval and consent to participate}

All procedures followed were following the ethical standards of the responsible committee on human experimentation (Research Ethics Committees of Wuhan Union Hospital, Tongji Medical College, Huazhong University of Science and Technology) and with the Helsinki Declaration of 1964 and later versions.

\section{Consent for publication}

Not applicable.

\section{Competing interests}

The authors declare that they have no competing interests.

\section{Author details}

${ }^{1}$ Cancer Center, Union Hospital, Tongji Medical College, Huazhong University of Science and Technology, Wuhan 430022, China. ${ }^{2}$ Institute of Hematology, Union Hospital, Tongji Medical College, Huazhong University of Science and Technology, No. 1277 Jiefang Avenue, Hubei 430022 Wuhan, China.

Received: 7 October 2020 Accepted: 1 June 2021

Published online: 12 June 2021

\section{References}

1. Harbeck N, Gnant M. Breast cancer. Lancet. 2019:389(10074):1134-50.

2. Siegel RL, Miller KD. Cancer statistics. CA Cancer J Clin. 2020;70(1):7-30.

3. Waks AG, Winer EP. Breast cancer treatment: a review. Jama. 2019:321(3):288-300.

4. Galon J, Bruni D. Tumor immunology and tumor evolution: intertwined histories. Immunity. 2020;52(1):55-81.

5. Balkwill F, Mantovani A. Inflammation and cancer: back to Virchow? Lancet (London, England). 2001;357(9255):539-45.

6. Balkwill F, Charles KA, Mantovani A. Smoldering and polarized inflammation in the initiation and promotion of malignant disease. Cancer Cell. 2005; 7(3):211-7

7. Denkert C, Loibl S, Noske A, Roller M, Müller BM, Komor M, Budczies J, Darb-Esfahani S, Kronenwett R, Hanusch C, et al. Tumor-associated lymphocytes as an independent predictor of response to neoadjuvant chemotherapy in breast cancer. J Clin Oncol. 2010;28(1):105-13.

8. Loi S, Sirtaine N, Piette F, Salgado R, Viale G, Van Eenoo F, Rouas G, Francis $P$, Crown JP, Hitre $E$, et al. Prognostic and predictive value of tumorinfiltrating lymphocytes in a phase III randomized adjuvant breast cancer trial in node-positive breast cancer comparing the addition of docetaxel to doxorubicin with doxorubicin-based chemotherapy: BIG 02-98. J Clin Oncol. 2013·31(7):860-7.

9. Adams S, Gray RJ, Demaria S, Goldstein L, Perez EA, Shulman LN, Martino S, Wang M, Jones VE, Saphner TJ, et al. Prognostic value of tumor-infiltrating lymphocytes in triple-negative breast cancers from two phase III randomized adjuvant breast cancer trials: ECOG 2197 and ECOG 1199. J Clin Oncol. 2014;32(27):2959-66.

10. Loi S, Michiels S, Salgado R, Sirtaine N, Jose V, Fumagalli D, KellokumpuLehtinen PL, Bono P, Kataja V, Desmedt C, et al. Tumor infiltrating lymphocytes are prognostic in triple negative breast cancer and predictive for trastuzumab benefit in early breast cancer: results from the FinHER trial. Ann Oncol. 2014;25(8):1544-50.

11. Sharonov GV, Serebrovskaya EO, Yuzhakova DV, Britanova OV, Chudakov DM. B cells, plasma cells and antibody repertoires in the tumour microenvironment. Na Rev Immunol. 2020;20(5):294-307.
12. Wennhold K, Shimabukuro-Vornhagen A, von Bergwelt-Baildon MB. Cell-based cancer immunotherapy. Transfusion Med Hemotherapy. 2019:46(1):36-46

13. Qin ZH, Richter G, Schuler T, Ibe S, Cao XT, Blankenstein T. B cells inhibit induction of T cell-dependent tumor immunity. Nat Med. 1998;4(5):627-30.

14. Petitprez F, de Reynies A, Keung EZ, Chen TW, Sun CM, Calderaro J, Jeng YM, Hsiao LP, Lacroix L, Bougouin A, et al. B cells are associated with survival and immunotherapy response in sarcoma. Nature. 2020;577(7791):556-60.

15. Helmink BA, Reddy SM, Gao J, Zhang S, Basar R, Thakur R, Yizhak K, SadeFeldman M, Blando J, Han G, et al. B cells and tertiary lymphoid structures promote immunotherapy response. Nature. 2020;577(7791):549-55.

16. Cabrita R, Lauss M, Sanna A, Donia M, Skaarup Larsen M, Mitra S, Johansson I, Phung B, Harbst K, Vallon-Christersson J, et al. Tertiary lymphoid structures improve immunotherapy and survival in melanoma. Nature. 2020;577(7791):561-5.

17. Lu Y, Zhao Q, Liao JY, Song E, Xia Q, Pan J, Li Y, Li J, Zhou B, Ye Y, et al. Complement signals determine opposite effects of B cells in chemotherapyinduced immunity. Cell. 2020:180(6):1081-97 e1024.

18. Hollern DP, Xu N, Thennavan A, Glodowski C, Garcia-Recio S, Mott KR, He X, Garay JP, Carey-Ewend K, Marron D, et al. B cells and T follicular helper cells mediate response to checkpoint inhibitors in high mutation burden mouse models of breast cancer. Cell. 2019;179(5):1191-206 e1121.

19. Wouters MCA, Nelson BH. Prognostic significance of tumor-infiltrating B cells and plasma cells in human cancer. Clinical Cancer Res. 2018;24(24):6125-35

20. Shen M, Wang J, Ren X. New insights into tumor-infiltrating B lymphocytes in breast cancer: clinical impacts and regulatory mechanisms. Front Immunol. 2018;9:470

21. Zhang Z, Zhu Y, Wang Z, Zhang T, Wu P, Huang J. Yin-yang effect of tumor infiltrating B cells in breast cancer: fFrom mechanism to immunotherapy. Cancer Lett. 2017:393:1-7.

22. Arias-Pulido H, Cimino-Mathews A, Chaher N, Qualls C, Joste N, Colpaert C, Marotti JD, Foisey M, Prossnitz ER, Emens LA, et al. The combined presence of CD20 + B cells and PD-L1 + tumor-infiltrating lymphocytes in inflammatory breast cancer is prognostic of improved patient outcome. Breast Cancer Res Treatment. 2018:171(2):273-82.

23. Boissière-Michot F, Jacot W, Fraisse J, Gourgou S, Timaxian C, Lazennec G. Prognostic value of CXCR2 in breast cancer. Cancers. 2020;12(8):2076.

24. Schmidt M, Böhm D, von Törne C, Steiner E, Puhl A, Pilch H, Lehr HA, Hengstler JG, Kölbl H, Gehrmann M. The humoral immune system has a key prognostic impact in node-negative breast cancer. Cancer Res. 2008;68(13):5405-13.

25. Mahmoud SM, Lee AH, Paish EC, Macmillan RD, Ellis IO, Green AR. The prognostic significance of B lymphocytes in invasive carcinoma of the breast. Breast Cancer Res Treatment. 2012:132(2):545-53.

26. Miligy I, Mohan P, Gaber A, Aleskandarany MA, Nolan CC, Diez-Rodriguez M, Mukherjee A, Chapman C, Ellis IO, Green AR, et al. Prognostic significance of tumour infiltrating B lymphocytes in breast ductal carcinoma in situ. Histopathology. 2017;71(2):258-68.

27. Dickersin K, Scherer R, Lefebvre C. Identifying relevant studies for systematic reviews. BMJ 1994:309(6964):1286-91.

28. Liberati A, Altman DG, Tetzlaff J, Mulrow C, Gøtzsche PC, loannidis JP, Clarke M, Devereaux PJ, Kleijnen J, Moher D. The PRISMA statement for reporting systematic reviews and meta-analyses of studies that evaluate health care interventions: explanation and elaboration. J Clin Epidemiol. 2009;62(10):e1-34

29. Parmar MK, Torri V, Stewart L. Extracting summary statistics to perform meta-analyses of the published literature for survival endpoints. Stat Med. 1998;17(24):2815-34

30. Stang A. Critical evaluation of the Newcastle-Ottawa scale for the assessment of the quality of nonrandomized studies in meta-analyses. Eur J Epidemiol. 2010:25(9):603-5.

31. Garaud S, Buisseret L, Solinas C, Gu-Trantien C, de Wind A, Van den Eynden G, Naveaux C, Lodewyckx JN, Boisson A, Duvillier H, et al. Tumor infiltrating B-cells signal functional humoral immune responses in breast cancer. JCl insight. 2019;5(18):e129641.

32. Mohammed ZM, Going JJ, Edwards J, Elsberger B, McMillan DC. The relationship between lymphocyte subsets and clinico-pathologica 
determinants of survival in patients with primary operable invasive ductal breast cancer. British J Cancer. 2013;109(6):1676-84.

33. Yu H, Yang J, Jiao S, Wang J. Prognostic value of B lymphocyte infiltration in breast cancer. Nan fang yi ke da xue xue bao J Southern Med Univ. 2013;33(5):750-5.

34. XuY, Lan S, Zheng Q. Prognostic significance of infiltrating immune cell subtypes in invasive ductal carcinoma of the breast. Tumori. 2018;104(3):196-201.

35. Yeong J, Lim JCT, Lee B, Li H, Chia N, Ong CCH, Lye WK, Putti TC, Dent R, Lim E, et al. High densities of tumor-associated plasma cells predict improved prognosis in triple negative breast cancer. Front Immunol. 2018;9:1209.

36. Mittal S, Brown NJ, Holen I. The breast tumor microenvironment: role in cancer development, progression and response to therapy. Expert Rev Mol Diagn. 2018;18(3):227-43.

37. Azizi E, Carr AJ, Plitas G, Cornish AE, Konopacki C, Prabhakaran S, Nainys J, Wu K, Kiseliovas V, Setty M, et al. Single-cell map of diverse immune phenotypes in the breast tumor microenvironment. Cell. 2018;174(5):1293308.e1236.

38. St Paul M, Ohashi PS. The roles of CD8(+) T cell subsets in antitumor immunity. Trends Cell Biol. 2020;30(9):695-704.

39. Largeot A, Pagano G, Gonder S, Moussay E, Paggetti J. The B-side of cancer immunity: the underrated tune. Cells. 2019;8(5):449.

40. Chen XY, Yeong J, Thike AA, Bay BH, Tan PH. Prognostic role of immune infiltrates in breast ductal carcinoma in situ. Breast Cancer Res Treatment. 2019;177(1):17-27.

41. Zhao KL, Yang XJ, Jin HZ, Zhao L, Hu JL, Qin WJ. Double-edge role of $B$ cells in tumor immunity: potential molecular mechanism. Curr Med Sci. 2019:39(5):685-9.

42. Tokunaga R, Naseem M, Lo JH, Battaglin F, Soni S, Puccini A, Berger MD, Zhang W, Baba H, Lenz HJ. B cell and B cell-related pathways for novel cancer treatments. Cancer Treatment Rev. 2019;73:10-9.

43. Liu M, Sun Q, Wang J, Wei F, Yang L, Ren X. A new perspective: exploring future therapeutic strategies for cancer by understanding the dual role of B lymphocytes in tumor immunity. Int J Cancer. 2019;144(12):2909-17.

44. Namm JP, Li Q, Lao X, Lubman DM, He J, Liu Y, Zhu J, Wei S, Chang AE. B lymphocytes as effector cells in the immunotherapy of cancer. J Surg Oncol. 2012;105(4):431-5.

45. Li Q, Grover AC, Donald EJ, Carr A, Yu J, Whitfield J, Nelson M, Takeshita N, Chang AE. Simultaneous targeting of CD3 on T cells and CD40 on B or dendritic cells augments the antitumor reactivity of tumor-primed lymph node cells. J Immunol. 2005:175(3):1424-32.

46. Li Q, Teitz-Tennenbaum S, Donald EJ, Li M, Chang AE. In vivo sensitized and in vitro activated $B$ cells mediate tumor regression in cancer adoptive immunotherapy. J Immunol. 2009;183(5):3195-203.

47. Li Q, Lao XM, Pan Q, Ning N, Yet J, Xu YX, Li SP, Chang AE. Adoptive transfer of tumor reactive $B$ cells confers host T-cell immunity and tumor regression. Clin Cancer Res. 2011;17(15):4987-95.

48. Tao HM, Lu L, Xia Y, Dai F, Wang Y, Bao YY, Lundy SK, Ito F, Pan Q, Zhang XL, et al. Antitumor effector B cells directly kill tumor cells via the Fas/FasL pathway and are regulated by IL-10. Eur J Immunol. 2015;45(4):999-1009.

49. Xia Y, Tao H, Hu Y, Chen Q, Chen X, Xia L, Zhou L, Wang Y, Bao Y, Huang S, et al. IL-2 augments the therapeutic efficacy of adoptively transferred $B$ cells which directly kill tumor cells via the CXCR4/CXCL12 and perforin pathways. Oncotarget. 2016;7(37):60461-74.
50. Lapointe R, Bellemare-Pelletier A, Housseau F, Thibodeau J, Hwu P. CD40stimulated $B$ lymphocytes pulsed with tumor antigens are effective antigen-presenting cells that can generate specific $T$ cells. Cancer Res. 2003;63(11):2836-43.

51. Colluru VT, McNeel DG. B lymphocytes as direct antigen-presenting cells for anti-tumor DNA vaccines. Oncotarget. 2016;7(42):67901-18.

52. Candolfi M, Curtin JF, Yagiz K, Assi H, Wibowo MK, Alzadeh GE, Foulad D, Muhammad AK, Salehi S, Keech N, et al. B cells are critical to T-cell-mediated antitumor immunity induced by a combined immunestimulatory/conditionally cytotoxic therapy for glioblastoma. Neoplasia. 2011;13(10):947-60

53. Pavoni E, Monteriu G, Santapaola D, Petronzelli F, Anastasi AM, Pelliccia A, D'Alessio V, De Santis R, Minenkova O. Tumor-infiltrating B lymphocytes as an efficient source of highly specific immunoglobulins recognizing tumor cells. BMC Biotechnol. 2007;7:70.

54. Sautes-Fridman C, Petitprez F, Calderaro J, Fridman WH. Tertiary lymphoid structures in the era of cancer immunotherapy. Nat Rev Cancer. 2019:19(6):307-25

55. Sarvaria A, Madrigal JA, Saudemont A. B cell regulation in cancer and anti-tumor immunity. Cell Mol Immunol. 2017:14(8):662-74.

56. Ye L, Zhang Q, Cheng Y, Chen X, Wang G, Shi M, Zhang T, Cao Y, Pan H, Zhang $L$, et al. Tumor-derived exosomal HMGB1 fosters hepatocellular carcinoma immune evasion by promoting TIM-1 $(+)$ regulatory B cell expansion. J immunother Cancer. 2018;6(1):145.

57. Zhang C, Xin H, Zhang W, Yazaki PJ, Zhang Z, Le K, Li W, Lee H, Kwak L, Forman $S$, et al. CD5 binds to interleukin-6 and induces a feed-forward loop with the transcription factor STAT3 in B cells to promote cancer. Immunity. 2016;44(4):913-23.

58. Xiao X, Lao XM, Chen MM, Liu RX, Wei Y, Ouyang FZ, Chen DP, Zhao XY, Zhao Q, Li XF, et al. PD-1 hi identifies a novel regulatory B-cell population in human hepatoma that promotes disease progression. Cancer Discov. 2016;6(5):546-59.

59. Pylayeva-Gupta Y, Das S, Handler JS, Hajdu CH, Coffre M, Koralov SB, BarSagi D. IL35-producing B cells promote the development of pancreatic neoplasia. Cancer Discov. 2016;6(3):247-55.

60. Zhang Y, Gallastegui N, Rosenblatt JD. Regulatory B cells in anti-tumor immunity. Int Immunol. 2015;27(10):521-30.

61. Ishigami E, Sakakibara M, Sakakibara J, Masuda T, Fujimoto H, Hayama S, Nagashima T, Sangai T, Nakagawa A, Nakatani Y, et al. Coexistence of regulatory $B$ cells and regulatory $T$ cells in tumor-infiltrating lymphocyte aggregates is a prognostic factor in patients with breast cancer. Breast Cancer. 2019:26(2):180-9.

62. Wu H, Xia L, Jia D, Zou H, Jin G, Qian W, Xu H, Li T. PD-L1 (+) regulatory B cells act as a T cell suppressor in a PD-L1-dependent manner in melanoma patients with bone metastasis. Mol Immunol. 2020;119:83-91.

\section{Publisher's Note}

Springer Nature remains neutral with regard to jurisdictional claims in published maps and institutional affiliations.

Ready to submit your research? Choose BMC and benefit from

- fast, convenient online submission

- thorough peer review by experienced researchers in your field

- rapid publication on acceptance

- support for research data, including large and complex data types

- gold Open Access which fosters wider collaboration and increased citations

- maximum visibility for your research: over 100M website views per year

At BMC, research is always in progress.

Learn more biomedcentral.com/submissions 